\title{
Scholarly Publication by University Librarians: A Study at Penn State
}

\section{Richard L. Hart}

\begin{abstract}
The amount of scholarly publication that is required of academic librarians is thought to vary among different types of colleges and universities. The present study looks in detail at the aggregated publishing record of the librarians at Penn State University, an institution that requires publication as a condition of continued employment. Findings indicate that Penn State librarians are quite productive in terms of the number of publications they contribute to the literature, and they are strongly committed to research. Evidence suggests that increasing demands for publication have served to influence both the quantity and the quality of librarians' publications in recent years.
\end{abstract}

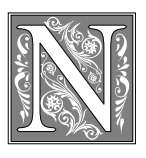

umerous studies have described various characteristics of academic librarians and their scholarly publications. In general, such studies look at a large group of publications from librarians who are employed at a wide variety of colleges and universities. Another strategy that may prove useful is to make a detailed study of the scholarly publications of librarians at a single institution. This narrow focus is particularly appropriate when looking at trends in scholarly publication because the type of college or university in which a faculty member works has been shown to be a key factor in influencing his or her publication patterns. ${ }^{1}$

This study attempts to further investigate the subject of librarians as scholarly authors by focusing on the output of the librarians at a single university-Penn State University. Penn State librarians are required to publish in order to be successful in their quest for promotion and tenure, and anecdotal evidence suggests that these librarians believe the expectations for publication have increased dramatically in the past few years. Because previous studies have shown that most academic librarians are not required to publish, Penn State librarians are not seen as being typical of academic librarians, and the findings of this study cannot be generalized to other colleges or universities. However, a detailed look at the librarians at a single institution should lead to further understanding of academic librarians as a whole.

Although teaching faculty at American colleges and universities have been pressured to increase their production of scholarly books and articles in recent decades, it is not clear that the same has been true for academic librarians. ${ }^{2}$ Studies have analyzed and described the library literature, and looked at academic librarians as authors, but there is no clear-cut agreement that librarians face a "publishor-perish" scenario. In a study of authors of core journal articles, John M. Budd and Charles A. Seavey downplayed the im-

Richard L. Hart is the library director at Penn State Erie, The Behrend College; e-mail:rlh@psulias.psu.edu. 
pact of tenure pressure, concluding that "the publishing requirement in academic libraries quite clearly is not as widespread as may be commonly believed." 3 Similarly, Betsy Park and Robert Riggs found that less than 18 percent of all colleges and universities require that librarians publish as a stipulation for promotion and tenure. ${ }^{4}$ Even at research and doctorategranting universities, where publishing demands have traditionally been the most rigorous, it was recently found that only 64 percent of more than 200 campuses surveyed required their librarians to publish. ${ }^{5}$ Despite this, however, there is evidence to suggest that librarians are publishing more, although any direct link to tenure demands has yet to be established. Lois Buttlar concluded in a 1991 study that academic librarians were publishing more than in the past, and she speculated that this was due to tenure requirements. ${ }^{6}$ More recently, Barbara J. Via noted that the dramatic increase in the number of library journals, which can be traced to the 1960s and 1970s, continues. In fact, in the past fifteen years, there has been a "veritable explosion of new periodicals devoted to ever-narrower sub-topics of library and information science."7 Via suggests that this explosion may be due in some part to the ethos of "publish or perish."

\section{Studies have analyzed and described the library literature, and looked at academic librarians as authors, but there is no clear-cut agreement that librarians face a publish-or-perish scenario.}

This study examines librarians and their scholarly publications at an institution where the values of publish or perish are accepted. The focus of the study was twofold. First, it attempted to get a sense of the Penn State librarians' commitment to research and a description of their aggregate record of publication. Second, it looked for evidence of ways in which publishing patterns might be changing, with a special emphasis on journal articles. It was hypothesized that, over time, the number and quality of publications by librarians have increased as a result of growing tenure pressures.

\section{Methodology}

A common research design of studies that examine publishing patterns among librarians is to look at each article in the published library literature for a certain time period and for a specific group of journals. For instance, Paula D. Watson examined the articles in eleven library science journals over a five-year period, Buttlar collected data from sixteen journals over a two and a half years, and Budd and Seavey's larger study investigated authors in thirty-six journal titles over five years. ${ }^{8-10}$ This approach seems particularly good at providing a description of the state of the core library literature. However, one difficulty with this approach is that many librarian publications fall outside the journals under examination. For example, books, book chapters, and conference proceedings are omitted. Also omitted are journal articles in nonlibrary science journals, which have been shown to comprise nearly 25 percent of all librarian journal publications. ${ }^{11}$ Other studies, rather than taking the journal literature as their starting point, begin with specific librarians and examine all of their publications. Some studies, such as Pamela S. Bradigan and Carol A. Mularski's study of academic health sciences librarians, used a survey questionnaire combined with examination of each respondent's list of publications. ${ }^{12}$ And others, such as Karen E. Pettigrew and Paul T. Nicholls's study of library and information science faculty, have identified the names of their subjects and then collected publication data by means of a series of database searches. ${ }^{13}$

The population for this study comprised all librarians employed at Penn State as of the fall of 1998. Two primary methods of data collection were used. A short survey questionnaire was used to obtain both data on the librarians' attitudes toward publication and on certain 
demographic information such as years of experience and tenure status. In addition to the survey questionnaire, data on each librarian's publications were collected by examining the publications listed in each respondent's vita. The decision to use the vita as the primary means of publication information was based on the fact that Penn State librarians are known to keep their vitae, not only upto-date, but also on file in the offices of the university libraries. Along with the survey questionnaire, a release form was sent to each librarian. The release form gave the researcher permission to obtain the librarian's vita from the university library files. Those librarians who preferred not to sign the release form were asked to send a list of publications when they returned the questionnaire.

The Penn State University Libraries has a unique administrative structure in that it is composed of a system of libraries found at twenty-four campus locations throughout the state. By far, the largest library in the system is located at the University Park campus, which is home to more than 40,000 students. It is less widely known that another 38,000 students are found at the other twenty-three campuses, at locations such as Altoona, Erie, Hazelton, and Wilkes Barre. Generally, the libraries at these campuses serve populations ranging in size from 800 to 3,600 students and employ from two to six librarians. Librarians at all locations are subject to the same tenure and promotion criteria, including the requirement to publish.

\section{Findings}

In September 1998, a survey was sent to all full-time, tenure-track librarians at Penn State, with a single follow-up letter to those who had not responded within a few weeks. Two librarians were eliminated from the survey population because they were on leave. The response rate of 76 percent represents fifty-nine respondents out of a possible seventy-eight librarians surveyed. There appears to be some extremely modest evidence of re- sponse bias in terms of campus location and possession of tenure. Librarians at the University Park campus responded at a lower rate $(70 \%)$ than did those at other campus locations (84\%). And tenured librarians were somewhat less likely to respond $(73 \%)$ than were those without tenure $(79 \%)$. However, because campus location is strongly related to possession of tenure (74\% of University Park campus librarians have tenure, compared to only $45 \%$ of those at other locations), it is unclear which of these factors influenced a librarian's decision to respond to the survey or, indeed, whether these factors had any influence at all on the decision to respond. There was no difference in response rate by gender. In general, it appears that the respondents were representative of the survey population.

The questionnaire included a number of demographic variables that provided a description of the respondents. It revealed that this group of librarians possessed considerable professional experience. When asked how many years they had worked full-time as a librarian, the answers ranged from one to forty-three, which averaged out to sixteen years of full-time experience. Most of the respondents had worked at another library earlier in their career, and twenty-seven of them reported having spent more than three years at another institution. However, as a group, most of their careers have been spent at Penn State, which accounted for nearly 70 percent of their total years of professional experience. This is important because it was an assumption of this study that the publication patterns of these librarians reflected Penn State's promotion and tenure expectations. The fact that 70 percent of their professional experience was at Penn State lends support to this assumption.

\section{Commitment to Research}

The survey questionnaire included several questions designed to get a sense of the librarians' commitment to research. One question asked whether the respondent was "currently engaged in scholarly 
work which you expect to lead to a publication." Another question asked how many hours per month the respondent spends "on work related to research or scholarly activity." Eighty-three percent of the respondents indicated they were currently engaged in a scholarly project that they expected to lead to publication. The amount of time these librarians reported spending on research was considerable. The results of this question are shown in table 1 . On average, the librarians spend 19.8 hours per month on their research, and fully 12 percent reported spending more than thirty hours per month.

Another survey question asked respondents the extent to which they agreed with the statement that "the amount of research and publishing expected of Penn State librarians has increased over the past fifteen or twenty years." (The questionnaire encouraged younger librarians to respond to this question "based on their understanding of the history of these types of expectations.") A resounding 95 percent agreed (73\% strongly agreed, $22 \%$ moderately agreed) that publishing expectations have increased over the past fifteen to twenty years. This is viewed in part as a measure of the individual librarian's commitment to research because increased tenure pressures must be accepted and met if one is to remain employed at Penn State. Thus, these three indicators-the percentage of respondents currently working on a research project, the number of hours spent on research, and the nearly unanimous agreement on increased publishing pressuresserve to characterize Penn State librarians as a group that makes a considerable commitment to scholarly pursuits.

\section{Publishing Output}

Successful data collection for this study required not only the return of the questionnaire, but also examination of each respondent's list of publications. A list of publications was obtained for fifty-seven of the fifty-nine respondents. Most respondents signed a release form, and their

\begin{tabular}{|cc|}
\hline \multicolumn{2}{c|}{ TABLE 1} \\
Librarians' Time Spent on Research \\
\hline \hline Hours per Month & Percentage of Librarians \\
\hline $2-10$ & 32 \\
$11-20$ & 35 \\
$21-30$ & 21 \\
more than 30 & 12 \\
\hline Total & 100 \\
\hline
\end{tabular}

vita was then obtained from university files. Some provided a copy of their current vita when they returned the survey questionnaire. Two librarians responded to the survey but did not provide a list of publications. Several databases were searched in order to identify the publications of these two librarians, and the results have been included with those of the other respondents.

This study did not include book reviews as publications. Also omitted from the tally of publications were encyclopedia articles, entries in biographical dictionaries and similar brief reference contributions, articles that appeared as a regular column or editorial in a journal, and translations. Although these types of publications were well represented in the respondents' vitae, the focus of the study was on those types of publications that are thought to be most commonly accepted for promotion and tenure: refereed and nonrefereed journal articles, book chapters, conference proceedings, and four categories of book-length publications, including authored books, edited books, bibliographies, and technical reports. The imprecise definition of what constitutes a "refereed" journal has been noted in other studies. ${ }^{14}$ In the present study, the respondents defined what were "refereed" or "nonrefereed" journals. Penn State librarians use a standard format for their vitae that requires them to distinguish between these two types of publications. Review of the titles the librarians listed as either refereed or nonrefereed suggests that there is broad agreement among them as to these definitions. 


\begin{tabular}{|c|c|c|c|c|}
\hline \multicolumn{5}{|c|}{$\begin{array}{c}\text { TABLE } 2 \\
\text { Librarian Output by Type of Publication } \\
\end{array}$} \\
\hline Type of Publication & Number & $\begin{array}{c}\% \text { of Total } \\
\text { Publications }\end{array}$ & $\begin{array}{c}\text { Per Capita } \\
\text { Publications }\end{array}$ & $\begin{array}{l}\text { Librarians with } \\
\text { at least One } \\
\text { Publication }\end{array}$ \\
\hline Refereed articles & 203 & 38 & 3.4 & $85 \%$ \\
\hline Nonrefereed articles & 128 & 24 & 2.2 & $69 \%$ \\
\hline Book chapters & 75 & 14 & 1.3 & $49 \%$ \\
\hline Conference proceedings & 75 & 14 & 1.3 & $44 \%$ \\
\hline Authored books & 22 & 4 & .4 & $20 \%$ \\
\hline Bibliography (books) & 18 & 3 & .3 & $18 \%$ \\
\hline Edited books & 8 & 1.5 & .1 & $8 \%$ \\
\hline Technical report & 8 & 1.5 & .1 & $12 \%$ \\
\hline Total & 537 & 100.0 & 9.1 & \\
\hline
\end{tabular}

Table 2 provides a summary of the publications of the Penn State librarians. The table shows not only the total number and percentage of publications for each category, but also the percentage of respondents who had at least one publication of that type and the per capita publications per category. As would be expected, the most common type of publication is the journal article. The 203 refereed journal articles and 128 nonrefereed journal articles combine to make up 62 percent of the total publications. This is remarkably similar to results of a study of academic health sciences librarians, which found that 68 percent of their publications were journal articles. ${ }^{15}$ Four categories of booklength publications combine for 10 percent of the total. Book chapters and conference proceedings, produced at an identical rate, combine for the remaining 28 percent.

On average, the Penn State librarians reported publishing slightly more than nine publications each. This large per capita publication rate is substantially higher than what has been reported in previous studies. Aubrey Kendrick's study of academic business librarians reported an average of 1.4 items (excluding book reviews) per librarian over their careers. ${ }^{16}$ Bradigan and Mularksi found that health sciences librarians averaged 2.7 publications over a ten-year period. ${ }^{17}$ With an average of sixteen years of expe- rience and slightly more than nine publications, Penn State librarians have a career average of .56 publications per year.

\section{Changing Patterns}

Are patterns in publication changing? As noted above, in response to a survey question, 95 percent of the librarians agreed that publishing expectations have increased at Penn State in recent years. If that is indeed the case, further analysis of their publishing output may show that publication patterns are changing as a result of the institution's rising expectations. It was hypothesized that not only would the number of publications increase over time, but also that the quality of the publications, as defined by the number and percentage of refereed journal articles and by the number and percentage of journal articles found in the "core" library literature, would increase to meet rising tenure and promotion expectations.

To analyze publishing output, all publications were placed into one of two categories: those published before 1990, and those published between 1990 and 1998 . These categories were determined after the researcher had identified the year that represents the midpoint of this group's aggregate years of experience as full-time librarians. As a group, the librarians reported having 943 years of combined experience. As noted above, the average 


\section{TABLE 3}

A Comparison of Earlier and Later Publications

\begin{tabular}{lrcrcr}
\hline \hline Type of Publication & \multicolumn{2}{c}{$\begin{array}{c}\text { Before 1990 } \\
\text { \%of Total }\end{array}$} & \multicolumn{3}{c}{$\begin{array}{c}\text { 1990 to date } \\
\text { \% of Total }\end{array}$} \\
& $\underline{N}$ & $\begin{array}{c}\text { Publications } \\
\text { Publications }\end{array}$ & Change (\%) \\
\hline Refereed articles & 44 & 31 & 159 & 40 & +261 \\
Nonrefereed articles & 47 & 33 & 81 & 20 & +72 \\
Book chapters & 20 & 14 & 55 & 14 & +175 \\
Conference proceedings & 13 & 9 & 62 & 16 & +376 \\
Authored books & 10 & 7 & 12 & 3 & +20 \\
Bibliography (books) & 4 & 3 & 14 & 4 & +250 \\
Edited books & 2 & 1 & 6 & 2 & +200 \\
Technical reports & 3 & 2 & 5 & 1 & +66 \\
\hline Total & 143 & 100 & 394 & 100 & +175
\end{tabular}

number of years of experience in 1998 is nearly sixteen years. The midpoint of this group's experience (to the nearest year) is 1990; 464 years of their aggregate working lives as librarians fell before 1990, and 479 years fell between 1990 and 1998. This analysis makes the assumption that if the librarians' publishing attitudes and behaviors had remained constant over time, the two categories of publications should look similar. However, it was hypothesized that the two groups would not be similar, reflecting the changes in tenure pressure and the librarians' increased scholarly productivity over time in response to that pressure.

Table 3 shows the various categories of publication divided by date. The percentage increase in each category is substantial, and the results provide rather dramatic evidence of the way in which publishing output has increased. Particularly large percentage increases are noted for refereed articles, book chapters, conference proceedings, bibliographies, and edited books. It is particularly interesting to note the change in emphasis placed on the importance of refereed articles as opposed to nonrefereed articles. Before 1990, nonrefereed articles made up slightly more of the total publications than refereed ar- ticles (33\% and 31\%, respectively). However, after 1990, refereed articles outnumber nonrefereed articles by a ratio of two to one ( $40 \%$ and $20 \%$, respectively).

The increase in refereed journal articles, in terms of both the total number of articles and their proportion of total publications, serves as evidence not only of increasing publishing demands, but also of an improvement in the quality of the respondents' publications over time. Further evidence of the quality of the journal publications can be gauged by the degree to which articles are found in the "core" library literature. Several authors have defined a core of library journals in efforts to analyze the library literature. ${ }^{18}$ For this study, Budd and Seavey's list of thirty-six journal titles is used to define a core. ${ }^{19}$ It should be noted that most, but not all, of the thirty-six core titles are refereed journals. Table 4 summarizes Penn State librarians' contributions to the core library literature for earlier and later publications. Their contributions to core journals have increased in terms of both their

TABLE 4 Total Articles and Core Articles by Time Period

\begin{tabular}{lcc}
\hline \hline Time Period & Total Articles & Core Articles (\%) \\
\hline $\begin{array}{l}\text { Published before 1990 } \\
\text { Published between }\end{array}$ & 91 & $24(26.4)$ \\
1990 and 1998 & 240 & $97(40.4)$ \\
\hline
\end{tabular}


total contributions and the percent of their articles that are part of the core. This lends additional support to the hypothesis that the quality of publications has improved over time.

\section{"Inside" versus "Outside" the Library Literature}

It was not the original intent of this study to look at the articles "inside" or "outside" the library literature, nor was it expected that nearly 60 percent of all articles published between 1990 and 1998 would fall outside the core of library literature as defined in this study. It had been assumed that with strong publishing expectations at Penn State, a higher percentage of journal articles would be found in the core. Where are the articles to be found if not in the core library literature? To answer this question, both refereed and nonrefereed articles were examined.

The nonrefereed articles of the Penn State librarians, although outside the core as defined by thirty-six library science titles, are found almost exclusively in library-related publications. The journal most heavily represented in this category is College $\mathcal{E}$ Research Libraries News, with a total of twenty-one articles. Nine articles, the second highest total for a journal title, were reported in the Pennsylvania Library Association Bulletin. Similarly, many of the remaining articles are found in newsletters of various library organizations representing specialized areas of librarianship, such as archives, art, and business.

The refereed journal articles that fall outside the core represent a wide mix of publications. Fifty-five journal titles are represented. Of these, thirty-two titles are not indexed in Library Literature, indicating that they fall outside the subject areas of library and information science. However, the total number of articles found in these nonlibrary science journals is only thirty-seven since multiple contributions are made only infrequently to these outside journals. The subject areas covered by these journals are diverse. Examples of titles include American Entomologist,
Civil Engineering Education, Hospitality and Tourism Education, Irish Slavonic Studies, Journal of Higher Education, Journal of the Air and Waste Management Association, and Teaching Political Science. However, most of the refereed articles outside the core are found in journals that are indexed in $\mathrm{Li}$ brary Literature; fifty-seven articles are found in twenty-three titles, including Acquisitions Librarian, American Archivist, Information Technology and Libraries, Medical Reference Services Quarterly, Serials Review, and World Patent Information. Although these articles lie outside the core, they are in refereed journals devoted to library and information science. Perhaps this should not be surprising, considering Via's observation about the proliferation of library science journals with an ever-narrower focus.

\section{The picture that emerges from this study shows that Penn State librar- ians must be viewed as a highly active group in terms of research and scholarly publication.}

It seems clear that there is a shift away from publishing in journals outside library science. Overall, 18 percent of the librarians' refereed journal articles are found in journals that are not indexed in Library Literature. However, when divided by date, these comprise fully 36 percent of pre-1990 refereed articles, but only 13 percent of the total between 1990 and 1998.

\section{Conclusion}

The purpose of this study was to take a closer look at the characteristics of librarians and their publications at an institution where publishing expectations are strong. Although the results may not be used to draw generalizations about other academic libraries, it is quite possible that similar findings would be observed at other colleges and universities where tenure pressures have strengthened in recent years.

The picture that emerges from this study shows that Penn State librarians 
must be viewed as a highly active group in terms of research and scholarly publication. On average, each has produced slightly more than nine publications, including articles, book chapters, conference proceedings, and books. Considering the level of scholarly output, it is not surprising that Penn State librarians report spending an average of nearly twenty hours per month on research. Nor is it surprising that more than 80 percent report that they are currently at work on a project they expect to lead to publication.

Moreover, it is not surprising that the librarians in this study have authored more publications than other studies have reported. This study focuses on librarians at a single institution where expectations are known to be strong; other studies usually include librarians at a wide variety of colleges and universities with a wide variety of expectations. This study helps to confirm the notion that scholarly productivity is most strongly influenced by the context of one's employment. This has been shown to be true for teaching fac- ulty, ${ }^{20}$ and it has been suggested in the library literature that academic librarians publish more at institutions that require them to do so. ${ }^{21}$ At Penn State, there are strong expectations for publication and the substantial amount of publishing output that this study documents is not viewed as an unexpected result.

Penn State librarians present rather strong evidence that "the bar has been raised." There was nearly unanimous agreement among these librarians that publishing expectations at the university have increased substantially in the past two decades. Examination of their publications has confirmed that a dramatic increase in publication quantity and quality can be documented. All types of publications, including refereed and nonrefereed journal articles, book chapters, conference proceedings, and books, are being produced at a greater rate. There has been a noticeable shift to refereed journals and away from nonrefereed journals, and a considerably higher percentage of articles are being found in the core library literature.

\section{Notes}

1. J. Scott Long and Robert McGinnis, "Organizational Context and Scientific Productivity," American Sociological Review 46 (1981): 422-442.

2. Jack H. Schuster and Howard R. Bowen, "The Faculty at Risk," Change 17 (Sept./Oct. 1985): 13-21.

3. John M. Budd and Charles A. Seavey, "Characteristics of Journal Authorship by Academic Librarians," College and Research Libraries 51 (Sept. 1990): 469.

4. Betsy Park and Robert Riggs, "Tenure and Promotion: A Study of Practices by Institutional Type," Journal of Academic Librarianship 19 (May 1993): 72-77.

5. Pamela S. Bradigan and Carol A. Mularski, "Evaluation of Academic Librarians' Publications for Tenure and Promotion," Journal of Academic Librarianship 22 (Sept. 1996): 360-365.

6. Lois Buttlar, "Analyzing the Library Periodical Literature: Content and Authorship," College and Research Libraries 52 (Jan. 1991): 38-53.

7. Barbara J. Via, "Publishing in the Journal Literature of Library and Information Science: A Survey of Manuscript Review Processes and Acceptance," College and Research Libraries 57 (July 1996): 366.

8. Paula D. Watson, "Production of Scholarly Articles by Academic Librarians and Library School Faculty," College and Research Libraries 46 (July 1985): 334-342.

9. Buttlar, "Analyzing the Library Periodical Literature: Content and Authorship," 38-53. 470 .

10. Budd and Seavey, "Characteristics of Journal Authorship by Academic Librarians, 463-

11. A. Neil Yerkey, "Publishing in Library and Information Science: Audience, Subjects, Affiliation, Source, and Format," Library and Information Science Research 15 (1993): 165-184.

12. Pamela S. Bradigan and Carol A. Mularski, "Authorship Outlets of Academic Health Sciences Librarians," Bulletin of the Medical Library Association 80 (April 1992): 188-191.

13. Karen E. Pettigrew and Paul T. Nicholls, "Publication Patterns of LIS Faculty from 19821992: Effects of Doctoral Programs," Library and Information Science Research 16 (1994): 139-156. 
14. Via, "Publishing in the Journal Literature of Library and Information Science," 367-370; Pettigrew and Nicholls, "Publication Patterns of LIS Faculty from 1982-1992," 144. 189.

15. Bradigan and Mularski, "Authorship Outlets of Academic Health Sciences Librarians,"

16. Aubrey Kendrick, "A Comparison of Publication Output for Academic Business Librarians with and without Faculty Rank," Journal of Academic Librarianship 17 (July 1991): 147. 189.

17. Bradigan and Mularski, "Authorship Outlets of Academic Health Sciences Librarians,"

18. Buttlar, "Analyzing the Library Periodical Literature," 39-40; Budd and Seavey, "Characteristics of Journal Authorship by Academic Librarians," 464; Stuart Glogoff, "Reviewing the Gatekeepers: A Survey of Referees of Library Journals," Journal of the American Society for Information Science 39 (Nov. 1988): 401.

19. Budd and Seavey, "Characteristics of Journal Authorship by Academic Librarians," 470.

20. Long and McGinnis, "Organizational Context and Scientific Productivity," 439-441. 